\title{
Trends in medical and nonmedical immunization exemptions to measles-containing vaccine in Ontario: an annual cross-sectional assessment of students from school years 2002/03 to 2012/13
}

\author{
Sarah E. Wilson MD MSc, Chi Yon Seo Msc, Gillian H. Lim MSc, Jill Fediurek BScN MPH, \\ Natasha S. Crowcroft MD MSc(Cantab), Shelley L. Deeks MD MHSc
}

See CMAJ commentary at www.cmaj.ca/lookup/doi/10.1503/cmaj.150707

Abstract

Background: Under Ontario legislation, for select vaccine-preventable diseases nonimmunized or under-immunized students must undergo vaccination or provide a statement of exemption, or risk suspension from school. At the time of this assessment, these diseases included measles, mumps, rubella, diphtheria, tetanus and polio.

Methods: Exemptions data for the school years 2002/03 to 2012/13 were obtained from the Immunization Records Information System used in Ontario. Temporal trends were expressed for 7- and 17-year-old students by exemption classification (medical, prior immunity, religious or conscientious belief, total) at the provincial level, by school year and by birth cohort. Regional analysis was conducted for the 2012/13 school year. A temporal trend analysis of exemptions for measles-containing vaccines was performed by using a Poisson distribution with a 2 -sided test $(\alpha=5 \%)$.

Results: For both 7- and 17-year-old students, religious or conscientious exemptions for measles-containing vaccines significantly increased over the study period ( $p<0.001$ in both age groups), whereas medical exemptions decreased ( $p<0.001$ in both age groups). The trends were reproduced when examined by birth cohort. The percentage of Ontario students with any exemption classification (total exemptions) remained low $(<2.5 \%)$ during the study period, although considerable geographic variation was noted.

Interpretation: Ontario data suggest that nonmedical exemptions have increased during the last 11 years, consistent with trends reported elsewhere. The trend toward increasing religious or conscientious exemptions coupled with declining medical exemptions explains why total exemptions have remained stable or decreased at the provincial level. The prominent geographic variability in exemptions suggests that targeted interventions may be suitable for consideration.

$\mathrm{V}$ accine hesitancy is of increasing concern in Canada. In a 2011 Canadian survey of parental attitudes toward vaccination, half of parents felt that newer vaccines were less safe than older vaccines, and $43 \%$ indicated that they were more concerned about vaccine safety than they had been 5 years earlier. ${ }^{1}$ There is limited literature to characterize vaccine hesitancy in Canada, although work is progressing in this area. ${ }^{2}$ Investigators in the United States have found evidence of increasing nonmedical exemptions, ${ }^{3,4}$ which are presumed to reflect declining public confidence in vaccination, and studies have linked geographic areas with high exemptions to outbreaks of vaccine-preventable diseases. ${ }^{5,6}$ In Ontario, there are communities who are known to be nonaccepting of vaccination on the basis of their religious beliefs. Several such com- munities have been associated with recent vaccine-preventable disease outbreaks, including a pertussis outbreak in 2011 and a rubella outbreak in 2005 in southwestern Ontario. ${ }^{7,8}$

Ontario is Canada's most populous province (population 13.5 million), with 36 public health units that vary greatly in geographic size and population size and density. Under Ontario

Competing interests: None declared.

This article has been peer reviewed.

Correspondence to: Sarah Wilson, sarah.wilson@oahpp.ca

CMAJ Open 2015. DOI:10.9778/cmajo.20140088 
Public Health Standards, comprehensive immunization coverage assessment is done annually for all students within each public health unit. ${ }^{9}$ The Immunization of School Pupils Act requires that public health units maintain and assess records of immunization and exemptions for students under 18 years of age who reside in their jurisdiction. ${ }^{10}$ For select "designated diseases," students with incomplete immunization records must either undergo vaccination or provide a valid exemption statement, or risk school suspension. Measles, mumps, rubella, diphtheria, tetanus and polio have been long-standing designated diseases; in July 2014, varicella, invasive meningococcal disease and pertussis were added to the list. The original 1982 legislation permitted nonmedical exemptions only on religious grounds, but conscientious objections were added in a 1984 amendment. ${ }^{11}$ To register a nonmedical exemption, a notarized Statement of Conscience or Religious Belief must be completed and signed by the parent or guardian, or by the student him- or herself if 16 years of age or older. ${ }^{12}$ A Statement of Medical Exemption must be completed and signed by either a physician or a nurse practitioner. Medical exemptions are classified on the statement as being either detrimental to health or on the basis of laboratory confirmation of immunity for select diseases. ${ }^{13}$ Only New Brunswick has similarly comprehensive legislation pertaining to immunization requirements for school entry. ${ }^{14}$

Our objective was to describe immunization exemptions to measles-containing vaccines among Ontario students over the last 11 school years, and to compare the direction and size of trends in nonmedical and medical exemptions to those seen elsewhere. We chose to focus on exemptions to measles-containing vaccines for several reasons. First, we expected that there would be a greater number of medical exemptions, because measles-containing vaccines are live virus vaccines, and certain immune-compromising conditions are medical contraindications to vaccination. ${ }^{15}$ Second, we anticipated that vaccine-hesitant parents might be more concerned about measlescontaining vaccines than other vaccines because of the discredited hypothesis linking the measles-mumps-rubella (MMR) vaccine to autism. ${ }^{16}$ Third, media coverage of recent measles outbreaks in Canada has questioned the role of vaccine hesitancy in negatively affecting vaccine coverage and resulting in increased measles circulation. Ontario's routine surveillance of immunization exemptions provides an opportunity to assess the extent to which conscientious and religious exemptions have increased in recent years.

\section{Methods}

\section{Study design}

We examined immunization exemptions for measles-containing vaccine among 7 - and 17-year-old students separately for the period of 2002/03 to 2012/13. Since 2010, data from the Immunization Records Information System have been reported at the level of antigen (measles), rather than vaccine (MMR). Data from before 2010 were extracted by vaccine.

This project was assessed through Public Health Ontario's ethics screening process ${ }^{17}$ and was found to not require additional ethics review by Public Health Ontario's Ethics Review Board.

\section{Sources of data}

The Immunization Records Information System, a collection of provincially supported, decentralized databases, was used to support documentation and assessment of student immunization and exemption records in Ontario between 1992 and 2014. During this period, public health units annually provided data on vaccine coverage and exemptions, aggregated by antigen and birth cohort, to the provincial level for the purposes of surveillance. These historical reports, capturing school years 2002/03 to 2012/13, represent the data source for all analyses.

Provincial surveillance functions, including the surveillance of immunization coverage and exemptions, were transferred to Public Health Ontario in 2011. As a process of ensuring data quality, Public Health Ontario validates local coverage and exemptions data with public health units before their inclusion in reports and related analyses. Although a formal data validation step did not exist before 2011, staff would follow up with individual public health units in the event that any irregularities were noted.

To address the lack of routine validation before 2010/11, public health unit-specific exemption data from the period predating routine validation (2002/03 to 2010/11) were reviewed to identify public health units that may have archived data for 17-year-old students before submission to the province. Premature data archiving results in incomplete data and cohorts that are smaller than expected. To identify any such cohorts, any public health unit for which the cohort of 17 -year-old students was smaller than $50 \%$ of the cohort of 7 -year-old students, in any year, was flagged for further review. The birth cohort of the 17-year-old students was then assessed in relation to the size of the same cohort (i.e., same year of birth) in the previous school year, where available. If this information was not available, the size of the birth cohort comprising 16-year-old students was reviewed for the same school year. We excluded public health unit-specific data for a particular school year if the size of the birth cohort of 17 -year-old students was less than $60 \%$ of the size of the comparator birth cohort.

\section{Study population}

Owing to the scope of the Immunization of School Pupils Act, this analysis represents a population-based assessment of immunization exemptions in Ontario. We focused on students aged 7 and 17 years in accordance with Canadian guidelines on age cohorts for routine coverage assessment. ${ }^{18}$

\section{Outcomes}

Trends in exemptions were assessed by classification: medical (excluding prior immunity), prior immunity and conscience or religious belief. Students with a medical exemption on the basis of prior immunity have a distinct exemption classification and their data were examined separately. Because the statement submitted for nonmedical exemptions does not ask the individual to specify whether an exemption is on the basis of conscience or religious belief, we could not delineate between these two motivations. We defined trends in total exemptions 
as the sum of exemptions for medical reasons, because of prior immunity and on conscience or religious grounds.

In addition, we assessed temporal trends using a birth cohort approach that explored exemptions for 7- and 17-yearold students assessed by year of birth (1985 to 2005). Exemptions for students born between 1985 and 1995 were assessed when students were 17 years old; exemptions for students born between 1996 and 2005 were assessed when students were 7 years old. There was no double-counting of birth cohorts.

Public health unit-specific percentages among 7 year olds were determined for nonmedical and medical exemptions, excluding prior immunity, for measles-containing vaccine in the 2012/13 school year. Public health units were rank ordered in a non-nominal fashion from highest to lowest in terms of the percentage of 7 year olds with a nonmedical exemption to measles-containing vaccine, and a number was assigned to each of the 36 based on their relative ranking (ranked from highest to lowest). This number was preserved when assessing the distribution of public health units with regard to medical exemptions. Owing to limitations of the Immunization Records Information System, it was not possible to estimate the number of unique students with an exemption to any antigen in 2012/13 or school year or earlier.

\section{Statistical analysis}

The statistical significance of temporal trends was assessed using a Poisson distribution and a 2 -sided test $(\alpha=5 \%)$.

\section{Results}

Total exemptions were highest against polio-containing vaccine $(2.3 \%)$ and lowest against mumps and rubella $(1.4 \%)$ (Figure 1). Of the 3 categories of exemptions, exemptions on the basis of conscience or religious belief accounted for the greatest percentage of total exemptions, responsible for $89 \%$ of all exemptions registered in 2012/2013 among 7-year-old students (Figure 1, 13559 of 15307 students). Provincial estimates obscure prominent variability by individual public health unit, which ranged from $0.7 \%$ to $7.5 \%$ for exemptions due to

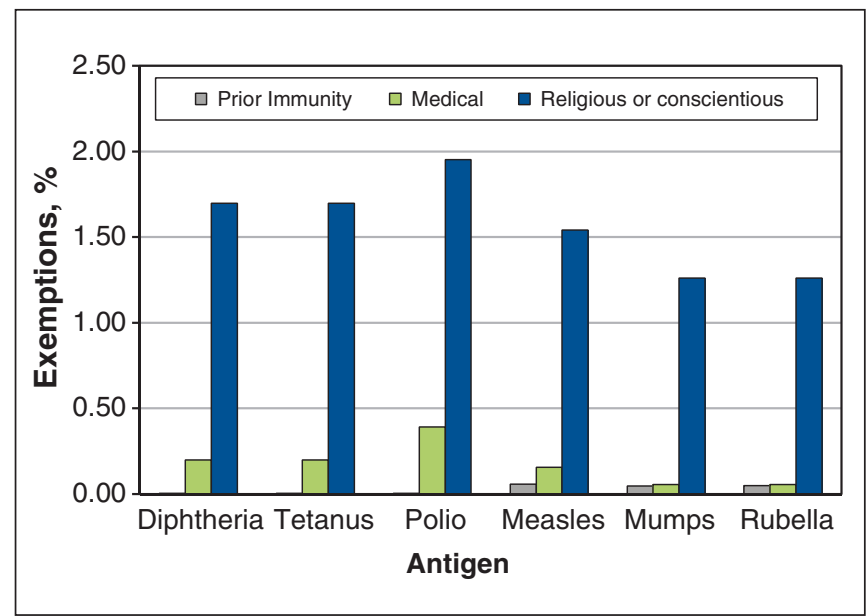

Figure 1: Immunization exemptions among 7-year-old students in Ontario for the $2012 / 13$ school year. conscience or religious beliefs (Appendix 1, available at www. cmajopen.ca/content/3/3/E317/suppl/DC1). Less variability was noted in medical exemptions (range $0 \%-1.8 \%$, Appendix 1). The provincial estimate for religious or conscientious exemption for measles-containing vaccine was $1.5 \%$, and the estimate for medical exemption was $0.2 \%$. Public health units with the highest percentages of nonmedical exemptions differed from those with the greatest percentages of students with medical exemptions.

Cleaning of historical exemptions data on the basis of birth cohort size resulted in the exclusion of 69 out of a total of 398 public health unit-specific estimates for 17-year-old students over the 11 years of analysis (Figure 2). The exclusions had no effect on the overall percentage of total exemptions across the study period for this age group: total exemptions were $1.8 \%$ with $(26586 / 1476321)$ and without (27 736/1 530165$)$ the aforementioned exclusions. When assessed by trends across school years, exemptions for conscience or religious belief increased among 17 -year-old students $(0.6 \%-1.1 \%, p<0.001)$, with a more pronounced decrease in medical exemptions $(0.8 \%-0.2 \%, p<0.001)$, resulting in a decrease in total exemptions over time $(1.9 \%-1.4 \%, p<0.001)$ (Table 1$)$. Similar trends were noted among 7 -year-old students (Table 2).

The birth cohort approach showed a doubling in the percentages of students with conscience or religious belief exemptions to measles-containing vaccine over a 20 -year period, from $0.6 \%$ among students born in 1985 to $1.5 \%$ for students born in $2005(p<0.001)$ and a significant decline in medical exemptions (from $0.8 \%$ for students born in 1985 to

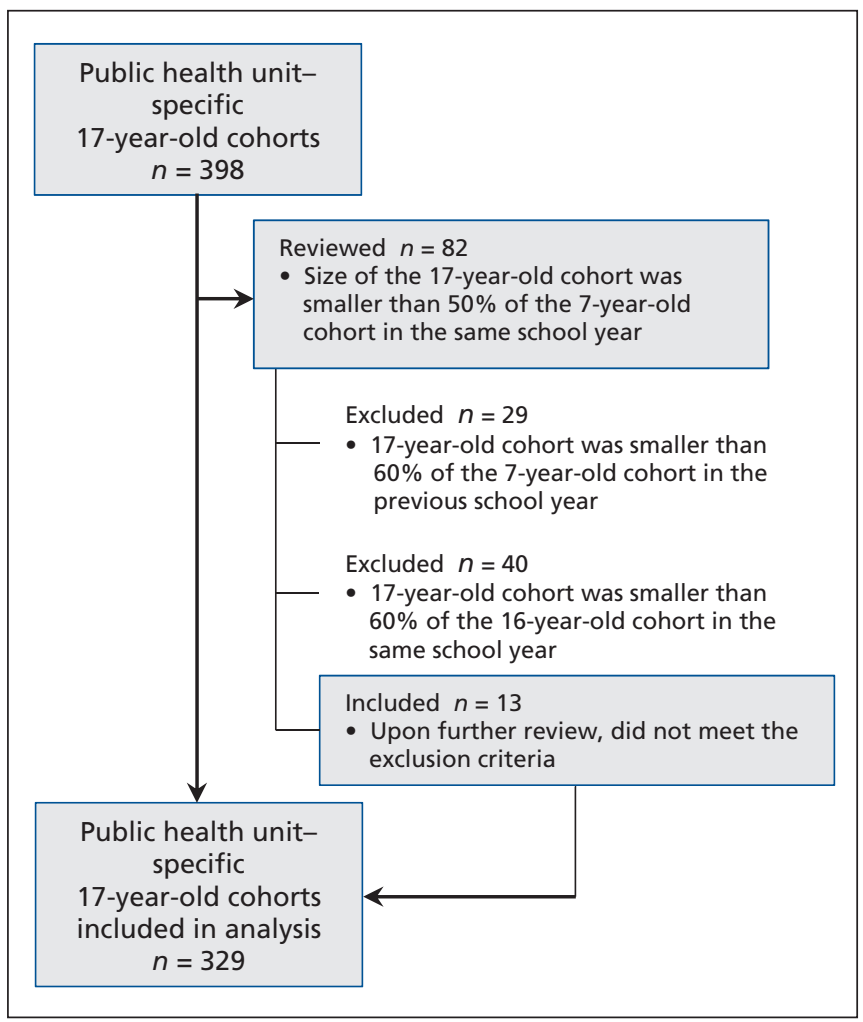

Figure 2: Data cleaning process to identify 17-year-old birth cohorts with incomplete data (2002/03 to 2012/13). 
$0.2 \%$ for students born in 2005, $p<0.001$ ) (Figures 3 and 4). In the 20 birth cohorts of interest, exemptions claimed on the basis of prior immunity to measles (i.e., from natural infection) decreased with time, from $0.5 \%$ to $0.1 \%(p<0.001)$ (data not shown).

\begin{tabular}{|lcccc|}
\hline \multirow{5}{*}{$\begin{array}{l}\text { Table 1: Temporal trends in immunization exemptions to } \\
\text { measles-containing vaccine among } \\
\text { Ontario during the 2002/03 to 2012/13 schoold students in } \\
\text { exemption classification }\end{array}$} \\
\cline { 2 - 5 } & \multicolumn{5}{c|}{ Proportion of students, \% } \\
\hline School & $\begin{array}{c}\text { Medical } \\
\text { exemptions }\end{array}$ & $\begin{array}{c}\text { Prior } \\
\text { immunity }\end{array}$ & $\begin{array}{c}\text { Religious or } \\
\text { conscientious } \\
\text { exemptions }\end{array}$ & $\begin{array}{c}\text { Total } \\
\text { exemptions }\end{array}$ \\
\hline $2002 / 03$ & 0.82 & 0.47 & 0.58 & 1.88 \\
\hline $2003 / 04$ & 0.74 & 0.47 & 0.74 & 1.95 \\
\hline $2004 / 05$ & 1.14 & 0.47 & 0.67 & 2.27 \\
\hline $2005 / 06$ & 0.76 & 0.39 & 0.93 & 2.08 \\
\hline $2006 / 07$ & 0.91 & 0.39 & 0.88 & 2.21 \\
\hline $2007 / 08$ & 0.72 & 0.31 & 1.11 & 2.14 \\
\hline $2008 / 09$ & 0.62 & 0.22 & 1.17 & 2.01 \\
\hline $2009 / 10$ & 0.54 & 0.16 & 1.16 & 1.86 \\
\hline $2010 / 11$ & 0.14 & 0.13 & 0.96 & 1.23 \\
\hline $2011 / 12$ & 0.17 & 0.12 & 0.95 & 1.23 \\
\hline $2012 / 13$ & 0.19 & 0.12 & 1.09 & 1.39 \\
\hline & $p<0.001$ & $p<0.001$ & $p<0.001$ & $p<0.001$ \\
\hline & & & & \\
\hline
\end{tabular}

Table 2: Temporal trends in immunization exemptions to measles-containing vaccine among 7-year-old students in Ontario during the $2002 / 03$ to $2012 / 13$ school years, by exemption classification

\begin{tabular}{|lcccc|}
\hline & \multicolumn{4}{c|}{ Proportion of students, \% } \\
\cline { 2 - 5 } $\begin{array}{l}\text { School } \\
\text { year }\end{array}$ & $\begin{array}{c}\text { Medical } \\
\text { exemptions }\end{array}$ & $\begin{array}{c}\text { Prior } \\
\text { immunity }\end{array}$ & $\begin{array}{c}\text { Religious/ } \\
\text { conscientious } \\
\text { exemptions }\end{array}$ & $\begin{array}{c}\text { Total } \\
\text { exemptions }\end{array}$ \\
\hline $2002 / 03$ & 0.51 & 0.07 & 1.05 & 1.63 \\
\hline $2003 / 04$ & 0.48 & 0.06 & 1.10 & 1.65 \\
\hline $2004 / 05$ & 0.38 & 0.09 & 1.15 & 1.62 \\
\hline $2005 / 06$ & 0.31 & 0.07 & 1.14 & 1.52 \\
\hline $2006 / 07$ & 0.29 & 0.07 & 1.32 & 1.68 \\
\hline $2007 / 08$ & 0.20 & 0.06 & 1.34 & 1.61 \\
\hline $2008 / 09$ & 0.21 & 0.08 & 1.41 & 1.70 \\
\hline $2009 / 10$ & 0.19 & 0.05 & 1.65 & 1.90 \\
\hline $2010 / 11$ & 0.17 & 0.05 & 1.42 & 1.64 \\
\hline $2011 / 12$ & 0.17 & 0.06 & 1.41 & 1.63 \\
\hline $2012 / 13$ & 0.16 & 0.06 & 1.54 & 1.75 \\
\hline & $p<0.001$ & $p<0.05$ & $p<0.001$ & $p<0.001$ \\
\hline
\end{tabular}

\section{Interpretation}

Our analysis provides insight into trends in vaccine refusal within Canada's most populous province and shows that nonmedical exemptions to measles-containing vaccine have significantly increased with time; however, the absolute proportion remains low, at less than $2 \%$. As shown by our more detailed assessment of the 2012/13 school year, regional variability is marked. Analyses at a smaller area level, such as individual schools, even among public health units with low levels of exemptions serve to further illustrate this trend, ${ }^{19}$ as does an analysis of exemptions by income quintile. ${ }^{20} \mathrm{We}$ were not able to explore this further at the provincial level owing to the limitations of the Immunization Records Information System.

A previous study of immunization exemptions in Ontario examined data from only 2 school years, was focused on the ratio of exemptions owing to conscience or religious beliefs as compared with medical exemptions and did not explore variability by public health unit. ${ }^{21}$ The trends seen in nonmedical exemptions in Ontario are comparable with those seen in the US, although in some cases the proportions are smaller. For example, in a recent analysis of secular trends in exemptions for personal belief among kindergarten students in California, the state-level exemption rate increased from $0.6 \%$ in 1994 to $2.3 \%$ in 2009 , a mean annual increase of $9.2 \% .^{4}$ Analyses from Michigan found the mean rate of nonmedical exemptions by census tract increased from $1.9 \%$ in 1991 to $5.2 \%$ in 2004. ${ }^{5}$ Regional variability in exemptions is well documented; in some US states, it is more marked than what we saw, with some counties documenting nonmedical exemption rates as high as $25 \% .^{3}$

We have found few studies in the literature that have examined medical exemptions ${ }^{22,23}$ and none that have examined temporal trends directly. Instead, their focus has been to assess the relation between medical exemptions and state-level policies or intervention studies targeting providers. ${ }^{22,23}$ Several hypotheses for the significant decline in medical exemptions noted in our analyses have been developed, including greater clinician awareness regarding true immunization contraindications versus precautions and expanded expert guidance on immunization practice in this area.. ${ }^{24}$ In the fourth edition of the Canadian Immunization Guide, released in 1994, the National Advisory Committee on Immunization recommended routine skin testing for any person with an egg allergy, with guidance to administer MMR using a graded challenge under continuous observation for those with a positive skin test result. ${ }^{25}$ This recommendation was revised in 1998 after a literature review found no evidence of increased risk of anaphylaxis associated with egg allergy. ${ }^{26}$ This change could explain the notable decrease in medical exemptions we saw in the birth cohorts born between 1993 and 1995. An alternate explanation for the decline in medical exemptions is Ontario parents possibly being more aware of the ability to opt out of immunization requirements through an exemption claimed on conscience or religious beliefs and thus making fewer requests for medical exemptions. Because medical exemptions owing to prior immunity are classified separately, declining numbers of children 
with naturally acquired measles antibody due to previous wildtype infection in the post-measles-elimination era cannot explain these trends.

Other investigators have found that for both medical and nonmedical exemptions, American states with more stringent administrative criteria are more likely to have lower rates of exemptions, and a lower rate of increase for nonmedical exemptions. ${ }^{22,27}$ In addition, states that have more stringent requirements for nonmedical exemptions are more likely to have higher rates of medical exemptions. ${ }^{22}$ With regard to administrative complexity to obtain a medical exemption, Ontario would be classified as "easy," scoring 1 out of a possible

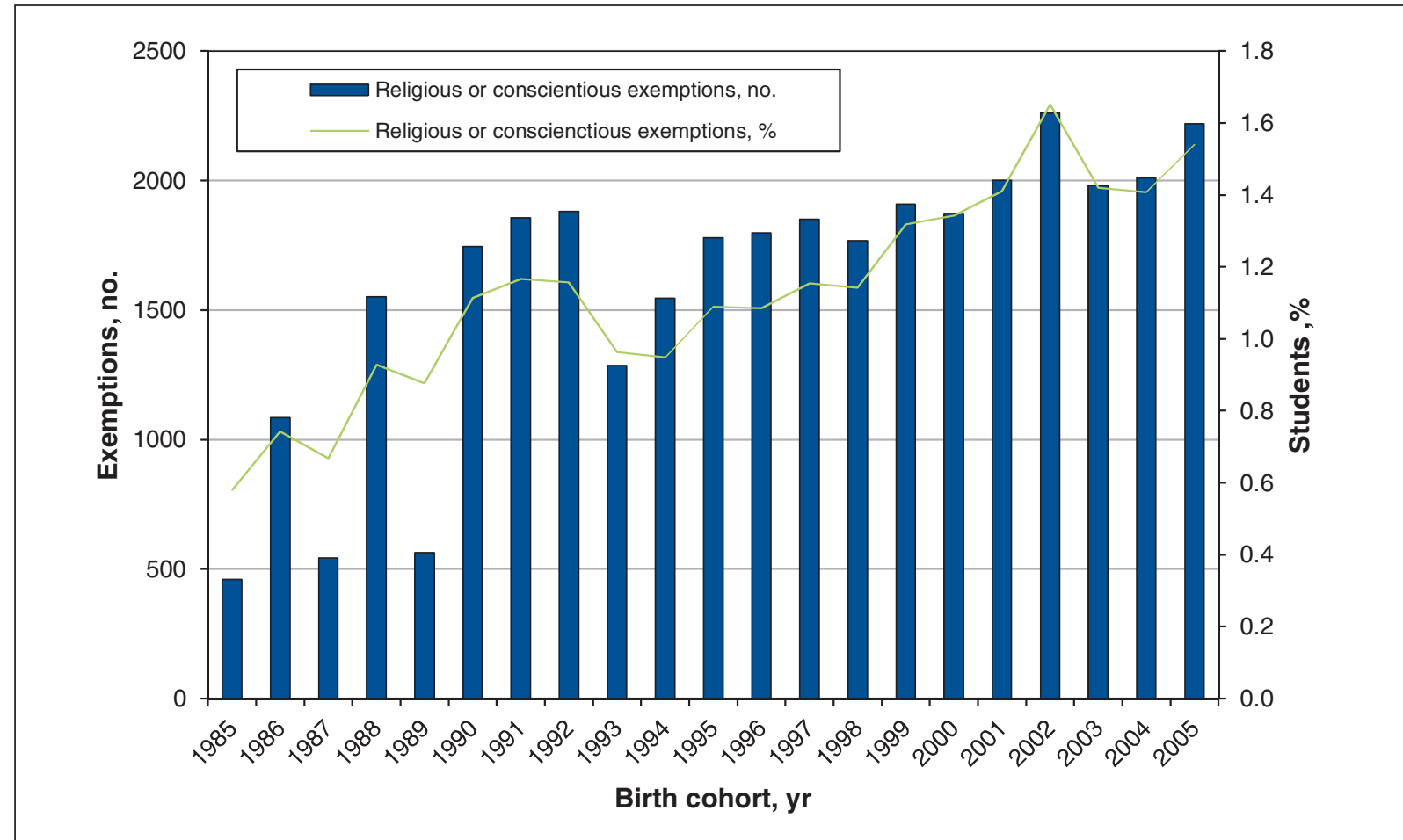

Figure 3: Temporal trends in immunization exemptions to measles-containing vaccine for religious or conscientious belief among Ontario students by year of birth.

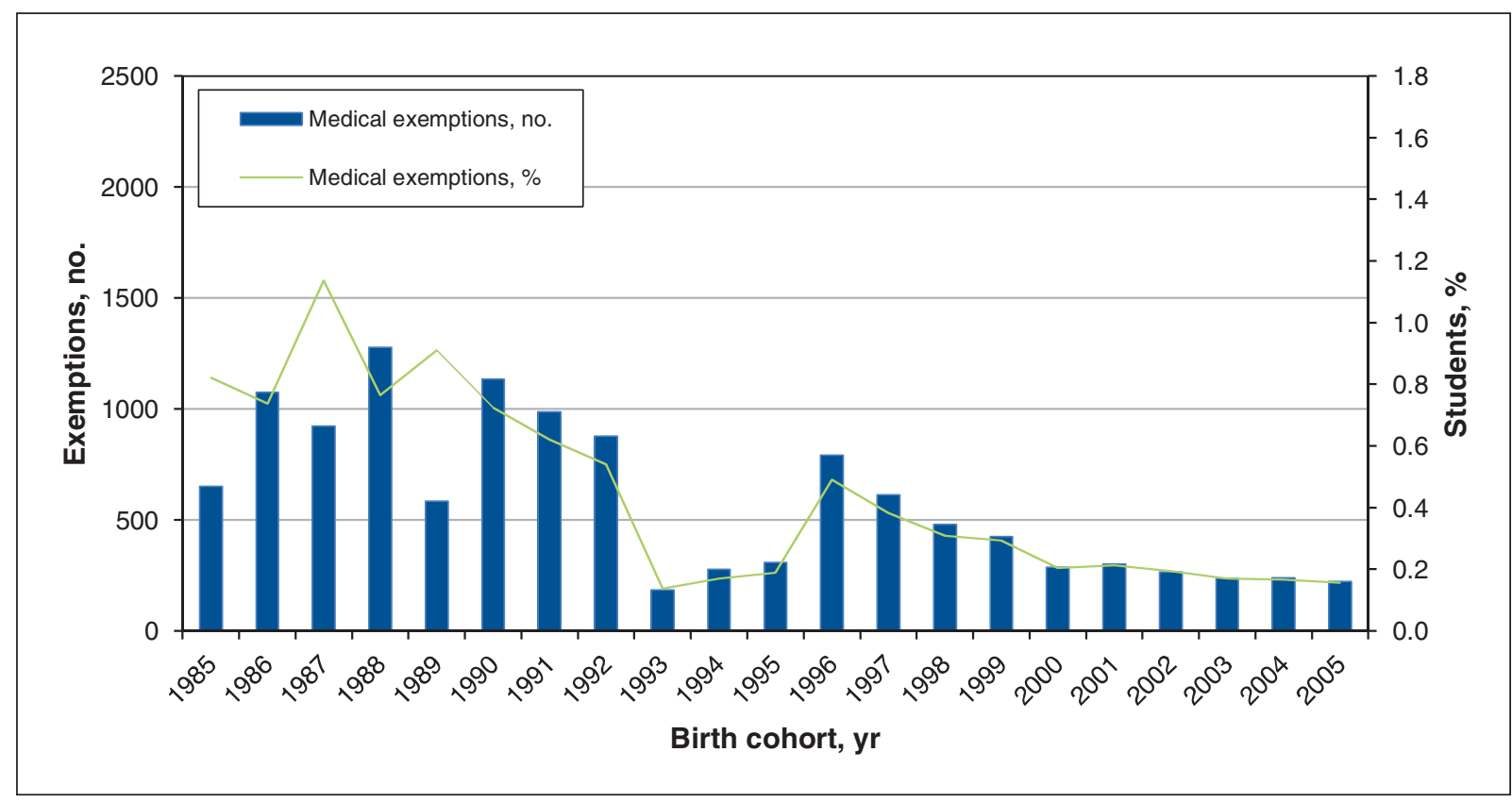

Figure 4: Temporal trends in medical exemptions to measles-containing vaccine among Ontario students by year of birth. 
6 criteria proposed by Stadlin and colleagues. ${ }^{22}$ Ontario's requirement for notarization of the parental statement of religious or personal belief objection, which as of July 2013 can be obtained online, would be classified as somewhere in the middle with respect to the administrative complexity to obtain a nonmedical exemption. ${ }^{27}$ However, many American states have more stringent processes, including health care provider documentation that the parent has been counselled regarding vaccine-preventable diseases and the risks and benefits of immunization. ${ }^{28}$ Other jurisdictions have adopted more targeted interventions focusing on geographical regions or providers associated with high levels of exemptions. ${ }^{23}$ Despite Ontario's legislation, 2-dose measles coverage was $88 \%$ among 7 -yearolds and 95\% among 17-year-olds in the 2012/13 school year, ${ }^{29}$ underscoring the need to have parallel approaches to both improve coverage and decrease exemptions, particularly among younger students.

\section{Strengths and limitations}

The strengths of our assessment lie with the comprehensive scope of the Immunization of School Pupils Act and the period captured by our analyses. The temporal trends in immunization exemptions we have described represent a population-level assessment of exemptions among Ontario's school-aged children for a period of 11 school years, representing children born over a 20-year period (1985 to 2005), during which notable shifts in public confidence in vaccination have occurred. However, this assessment has several limitations, which primarily relate to the lack of individual-level data available for analysis. Owing to the nature of the reports available at the provincial level, the public health unit is the smallest geographic level by which exemptions are reported, obscuring spatial clustering at a smaller area level. Other limitations include an inability to examine exemptions across the range of antigens listed in the act to document the percentage of Ontario students with an immunization exemption to at least one antigen. A further limitation was our inability to explore the individual immunization status of students with and without exemptions. Other studies have shown that some students with immunization exemptions will have undergone vaccination against the particular antigen. ${ }^{30,31}$ In contrast, data from Australia suggest that the percentage of children who have received no vaccines is about twice as high as the percentage of children who have a documented exemption. ${ }^{32}$ Finally, owing to the current wording of Ontario's legislation, exemptions due to conscience and religious belief are captured together, preventing us from delineating trends separately. We presume the increase we have seen has been driven by conscientious objection rather than by secular trends in religious beliefs or significant population expansion of religious groups known to be nonaccepting of vaccination.

\section{Conclusion}

This assessment confirms that nonmedical exemptions have increased in Ontario over the last 11 school years, which is consistent with trends reported elsewhere. The general trend toward increasing exemptions due to conscience or religious belief coupled with declining medical exemptions explains why total exemptions have remained stable or decreased at the provincial level. Despite relatively low levels of nonmedical exemptions, there is marked variability by public health unit, which suggests the potential role for targeted interventions. Such interventions should be tailored and sensitive to whether exemptions are on the basis of religious belief or conscientious objection. Future analyses to examine patterns of exemptions within public health units are needed and would support these efforts.

\section{References}

1. Survey of parents on key issues related to immunization. Toronto and Ottawa: Ekos Research Associates; 2011. Available: http://resources.cpha.ca/immunize. $\mathrm{ca} /$ data/1792e.pdf (accessed 2014 Feb. 14).

2. Laberge C, Guay M, Clément P, et al. Workshop on the cultural and religious roots of vaccine hesitancy: explanations and implications for the Canadian healthcare. Quebec: University of Sherbrooke/Victoria: University of Victoria; 2012. Available: www.usherbrooke.ca/dep-sciences-sante-communautaire/filead$\mathrm{min} /$ sites/dep-sciences-sante-communautaire/documents/Hesitation Vaccination/AfficheMG-anglais.pdf (accessed 2014 Feb. 14).

3. Omer SB, Salmon DA, Orenstein WA, et al. Vaccine refusal, mandatory immunization, and the risks of vaccine-preventable diseases. $N$ Engl $7 \mathrm{Med}$ 2009;360:1981-8.

4. Richards JL, Wagenaar BH, Van Otterloo J, et al. Nonmedical exemptions to immunization requirements in California: a 16-year longitudinal analysis of trends and associated community factors. Vaccine 2013;31:3009-13.

5. Omer SB, Enger K, Moulton L, et al. Geographic clustering of nonmedical exemptions to school immunization requirements and associations with geographic clustering of pertussis. Am 7 Epidemiol 2008;168:1389-96.

6. Atwell JE, Van Otterloo J, Zipprich J, et al. Nonmedical vaccine exemptions and pertussis in California, 2010. Pediatrics 2013;132:624-30.

7. Hahné S, Macey J, Tipples G, et al. Rubella outbreak in an unvaccinated religious community in the Netherlands spreads to Canada. Euro Surveill 2005; 10:E050519.1.

8. Deeks SL, Lim GH, Walton R, et al. Prolonged pertussis outbreak in Ontario originating in an under-immunized religious community. Can Dis Wkly Rep 2014;40:42-49. Available: www.phac-aspc.gc.ca/publicat/ccdr-rmtc/14vol40/ dr-rm40-03/dr-rm40-03-ont-eng.php (accessed 2015 May. 8).

9. Immunization management protocol. Toronto: Ontario Ministry of Health and Long-Term Care; 2013. Available: www.health.gov.on.ca/en/pro/programs/ publichealth/oph_standards/docs/immunization_management.pdf (accessed 2015 May. 8).

10. Immunization of School Pupils Act, R.R.O. 1990, Reg. 645. Available: www.e-laws .gov.on.ca/html/regs/english/elaws_regs_900645_e.htm (accessed 2015 May. 8).

11. Arnup K. 'Victims of vaccination'?: opposition to compulsory immunization in Ontario, 1900-90. Can Bull Med Hist 1992;9:159-76.

12. Statement of conscience or religious belief: Immunization of School Pupils Act. [affidavit form]. Toronto: Ontario Ministry of Health and Long-Term Care; 2013. Available: www.forms.ssb.gov.on.ca/mbs/ssb/forms/ssbforms.nsf/ GetFileAttach/014-4897-64E 1/\$File/4897-64E.pdf (accessed 2014 Feb. 14).

13. Statement of Medical Exemption. Immunization of School Pupils Act [form] Toronto: Ontario Ministry of Health and Long-Term Care; 2013. Available: www.forms.ssb.gov.on.ca/mbs/ssb/forms/ssbforms.nsf/GetFileAttach/014-4895 -64E 1/\$File/4895-64E.pdf (accessed 2014 Feb. 14).

14. Office of the Chief Medical Officer of Health (Public Health). Immunization program guide: policy 2.9 - required immunziation of school children. Fredericton (NB): Government of New Brunswick; 2013. Available: www2.gnb.ca/content/ dam/gnb/Departments/h-s/pdf/en/CDC/HealthProfessionals/NBIPG-policy_2-9 -e.pdf (accessed 2015 Aug. 19).

15. Canadian immunization guide [part 4: active vaccines: measles vaccine]. Ottawa: Public Health Agency of Canada; 2015 [modified]. Available: www.phac-aspc. gc.ca/publicat/cig-gci/p04-meas-roug-eng.php (accessed 2012 Nov. 30).

16. Brown KF, Long SJ, Ramsay M, et al. parents' decision-making about measlesmumps-rubella $(\mathrm{MMR})$ vaccine 10 years after the MMR-autism controversy: a qualitative analysis. Vaccine 2012;30:1855-64.

17. A framework for the ethical conduct of public health initiatives. Toronto: Ontario Agency for Health Protection and Promotion (Public Health Ontario); 2012.

18. National standards for immunization coverage assessment: recommendations from the Canadian Immunization Registry Network. Ottawa: Public Health Agency of Canada; 2015 [modified]. Available: www.phac-aspc.gc.ca/im/ nationalstandards-normenationales-eng.php (accessed 2015 May. 8).

19. Interactive: Which Toronto schools have the lowest vaccination rates? Global News 2014 Mar. 31. Available: http://globalnews.ca/news/1241099/ interactive-measles-vaccination-rates-for-every-school-in-toronto/?utm_source =twitterfeed\&utm_medium=twitter (accessed 2014 Aug. 12).

20. Board of Health report: inequalities and immunization rates in Toronto school 
children. Toronto: Toronto Public Health; 2012. Available: www.toronto.ca/ legdocs/mmis/2012/hl/bgrd/backgroundfile-44266.pdf (accessed 2014 Aug. 12).

21. Mah CL, Guttmann A, McGeer A, et al. Compulsory school-entry vaccination laws and exemptions: Who is opting out in Ontario and why does it matter? Health Policy 2010;5:37-46.

22. Stadlin S, Bednarczyk RA, Omer SB. Medical exemptions to school immunization requirements in the United States - association of state policies with medical exemption rates (2004-2011). F Infect Dis 2012;206:989-92.

23. Cruze AR, Zhang G, Thomas L, et al. Frequency and erroneous usage of temporary medical exemptions and knowledge of immunization guidelines among some Miami-Dade County Florida providers. Vaccine 2014;32:4500-4

24. Canadian immunization guide [part 2: vaccine safety: contraindications, precautions and concerns]. Ottawa: Public Health Agency of Canada; 2014 [modified]. Available: www.phac-aspc.gc.ca/publicat/cig-gci/p02-02-eng.php (accessed 2014 Aug. 12)

25. Canadian immunization guide. 4th ed. Ottawa: Health Canada; 1994.

26. Canadian immunization guide. 5th ed. Ottawa: Health Canada; 1998.

27. Omer SB, Richards JL, Ward M, et al. Vaccination policies and rates of exemption from immunization, 2005-2011. NEngl 7 Med 2012;367:1170-1.

28. California Legislative Information. Assembly Bill No. 2109: Communicable Disease Immunization Exemption. Available: http://leginfo.legislature.ca.gov/ faces/billNavClient.xhtml?bill_id=201120120AB2109 (accessed 2015 May. 8).

29. Immunization coverage report for school pupils. 2012-13 school year. Toronto: Ontario Agency for Health Protection and Promotion (Public Health Ontario); 2014.

30. Salmon DA, Moulton LH, Omer SB, et al. Factors associated with refusal of childhood vaccines among parents of school-aged children: a case-control study. Arch Pediatr Adolesc Med 2005;159:470-6.

31. Salmon DA, Sotir MJ, Pan WK, et al. Parental vaccine refusal in Wisconsin: a case-control study. WMF 2009;108:17-23.
32. Hull B, Dey A, Mahajan D, et al. NSW annual immunization coverage report, 2009. N S W Public Health Bull 2010;21:210-23.

Affiliations: Public Health Ontario (Wilson, Seo, Lim, Fediurek, Crowcroft, Deeks), Toronto, Ont.; Dalla Lana School of Public Health (Wilson, Crowcroft, Deeks); Department of Laboratory Medicine and Pathobiology (Crowcroft), University of Toronto, Toronto, Ont.

Contributors: Sarah Wilson conceived the study idea, directed the analyses and drafted the article. Chi Yon Seo and Gillian Lim were involved in the acquisition of data, and Chi Yon Seo executed the analyses presented. All of the authors substantially contributed to the interpretation of data, revised the manuscript critically for important intellectual content, gave final approval of the version to be published and agree to act as guarantors of the work.

Funding: This project was funded as part of the Public Health Ontario operational budget.

Acknowledgements: The authors thank the staff of Ontario's 36 public health units who are involved in the assessment of immunization records and the documentation of immunization exemptions, and colleagues at the Ontario Ministry of Health and Long-Term Care for their assistance with the interpretation of data and reports from the Immunization Records Information System.

Supplemental information: For reviewer comments and the original submission of this article, please see www.cmajopen.ca/content/3/3/ E317/suppl/DC1. 